\title{
Editorial
}

\section{VISUALIZACIÓN DE LA INFORMACIÓN CIENTÍFICA}

Es muy común escuchar por parte de muchos de los autores de artículos científicos, este estribillo: "no me quieren publicar mi artículo", ese preconcepto solamente es resultado de tratar de culpar a otros de nuestros propios errores y esto es solamente el producto de nuestro desconocimiento de las normas internacionales de publicación científica.

Una revista científica es la principal vitrina de presentación de información científica de una institución y presenta los trabajos de investigación que en ella se desarrollan; la calidad de la misma debe basarse en el respeto de las normas internacionales de publicación científica para que tenga el valor y reconocimiento de la comunidad científica y público objetivo a quien va dirigida, y de esa manera ser considerada como un documento que al respetar dichas normas, pueda ser considerada en las grandes bases de datos que acogen a las revistas de reconocido prestigio, esto solamente se puede lograr con el compromiso de parte de los autores de someterse a una evaluación y corrección de sus trabajos con la finalidad que puedan ser publicados.

En nuestra comunidad científica, existe la costumbre de querer tener siempre una "revista científica" en las instituciones académicas, pero se confunde dicho termino ya que muchas veces las autoridades que dirigen dichas instituciones gustan de figurar o tratan de colocar información institucional o poco relevante desde el punto de vista científico; estas situaciones no hacen más que desmerecer el aspecto científico de una revista y muchas veces la convierten en un boletín institucional. Si a eso le sumamos el poco interés de muchas instituciones, de apoyar dichas revistas, vemos que estos documentos pasan a ser elementos fluctuantes que aparecen y en corto plazo desaparecen, yendo a formar un archivo irregular de revistas que no mantienen periodicidad y que muchas veces cambian rápidamente de nombre, convirtiéndose en revistas fantasmas, que solamente están a disposición de las autoridades de turno para su figuración.

Tenemos que reconocer entonces que para poder visualizar nuestros trabajos a nivel nacional e internacional, tenemos que respetar las normas internacionales de publicación que las podemos encontrar en los formatos que las respectivas revistas adopten dentro de su esquema académico de publicación de artículos científicos, estilos de publicación como son los de la American Psychological Association (APA), Scientific Style Format of Council Biology Editors (CBE), Universidad de Chicago (CHICAGO), Universidad de Harvard (HARVARD), Estándar Internacional ISO 690 2 (ISO), Modern Language Association of America / Asociación del Lenguaje Moderno o Lengua Moderna de América (MLA), o el que adopta nuestra revista que es el del International Committee of Medical Journal Editors, o como comúnmente se le conoce como grupo Vancouver, y así existen muchos otros más.

En nuestro caso la revista Odontología Sanmarquina, va por el buen camino del respeto de las normas internacionales de publicación científica y cuenta con el apoyo institucional del Vicerrectorado de investigación para que se publique regularmente y sin intervencionismo, situación que prestigia la calidad de la misma y permite a los autores que tengan la tranquilidad que sus trabajos de investigación sean publicados en un documento confiable desde el punto de vista científico y ético que respeta las normas internacionales de publicación y que aspira a su inclusión en bases de datos confiables tanto nacionales, como regionales e internacionales garantizando la calidad de publicación, entonces solamente le quedaría a los autores, respetar las normas de publicación para evitar lo indicado al inicio y que sus artículos puedan ser publicados sin ningún inconveniente. 